\title{
Research on the Compensation Design of Civil Servants under Fairness Perspective ---Empirical Analysis based on a county in Liaoning Province
}

\author{
Wen-jing Wang ${ }^{1}$, Guang-wei Liu ${ }^{2}$ \\ ${ }^{1}$ Department of Politics and Law, Northeast Normal University, Changchun, 130117, China \\ ${ }^{2}$ Department of Business, Northeast Normal University, Changchun, 130117, China \\ wangwj672@nenu.edu.cn
}

\begin{abstract}
Through the pay status questionnaire of civil servants in a county in Liaoning Province, the authors find that there are 64.26 percent of the surveyed people believe that the compensation level of civil servants they current received is rather low. There are 20.96 percent of people consider that the remuneration they obtained is not match with their efforts, as well as 26.12 percent of respondents are unsure. Meanwhile, this paper analyses the fairness dilemma of civil servants under the perspective of compensation of individual fairness, level fairness and structural fairness. By drawing on foreign experience, the authors put forward corresponding reform ideas and concrete ways to improve compensation system of civil servants.
\end{abstract}

Index Terms - Compensation Design; Civil Servants; Compensation Fairness

\section{Introduction}

Income distribution system is the fundamental and basic institutional arrangement in economic and social development, it is also an important cornerstone of the socialist market economic system. Salary is the most important part of personal income. Compensation system of civil servants will not only affect the institution, it plays a demonstration role in corporations [1].

The total number of civil servants is more than 7 million people, the number of civil servants at the county level government agencies accounted for over $70 \%$. That is to say that there are more than 5 million civil servants working at the county level. Most civil servants will finish their career at Second Officer or Third or Associate Officer [2]. According to the current "Civil Servant Law", salaries of civil servants linked together with position. This not only led to slow growth of civil servants salaries, lack of a sense of fairness, decreased enthusiasm, even corruption [3-4].

Based on the fairness perspective, we try to answer the following questions: How is the compensation situation of current civil servants? How are they cognitive sense of income fairness? What is the fairness dilemma that civil servants have about compensation system? How to improve the civil servants pay system from the fairness perspective?

\section{Compensation Fairness Survey of Civil Servants}

The basic equity theory argues that fairness is a subjective evaluation and feelings. Studying pay equity is also subjective evaluation of workers when they received salaries.
We use the questionnaire designed by Fan (2006) to investigate the evaluation pay equity of the existing compensation system [5].

Considering Shenyang is the capital city of Liaoning Province, the level of economic development is in the middle class. In order to make the sample more general, we select a county in Shenyang as the subjects, the pay level of civil servants in this area can reflect the status of China's civil servants pay basic degree.

Based on representative and availability of data, we select 350 civil servants to investigate, 347 survey questionnaires were returned, of which there are 338 valid samples. Because it is roughly the same proportion of male and female samples (male $46.4 \%$,female $53.6 \%$ ), the interference of gender factors of the survey will not appear.

As there is not any authority questionnaire scale of pay equity at home and abroad, we design a questionnaire drawing on employees in enterprise called "China's Civil Servants Compensation Fairness Questionnaire ". The questionnaire is divided into four main parts. Civil Servants Pay Level Survey ( a total of ten questions ), Civil Servants Skills Pay Survey ( a total of eight questions ), Civil Servants Pay Fairness Survey (six questions ), Civil Servants Expectations Survey ( a total of four issue).

According to the questionnaire, we found the following four main issues:

Firstly, the compensation standard setting lacks encouragement. The current position is the main measure to increase the civil servants' salary level, in addition to graduate-level civil servants, the salary standard of civil servants is not be set according to the level of education, the effect of education incentive is not obvious. At the same time, promotion of civil servants titles is not given adequate attention in current compensation system, which suppressing the civil servants the enthusiasm of obtaining professional titles.

Secondly, the compensation fairness urgently needs to be improved. The survey results show that there are 64.26 percent of surveyed civil servants believed that the current salary is low, only 7.9 percent of civil servants consider their salary level is high. That indicates that the salary of civil servants is still lower than other industries relatively. Moreover, the selfassessment results from the civil servants show that 20.96 
percent of people consider that the remuneration they obtained is not match with their efforts, as well as 26.12 percent of respondents are unsure. That is to say, most of the civil servants believe that the efforts and remuneration is not proportional to let themselves feeling equity.

Thirdly, the pay structure of civil servants needs to be optimized. Compared with the results of self-assessment results of pay equity, $34 \%$ of current civil servants hold a neutral manner about the pay satisfaction, the majority of civil servants expressed satisfaction with the current compensation level. That reveals the reality that besides the basic salary, civil servants has high subsidies and Pan-welfare. When calculating the average salary of civil servants according to the job level classification, we find that during promoting from Section to Division level, the monetary remuneration increased only 53 Yuan, that doesn't consider their in-kind benefit, such as car consumption. Therefore, hidden income in the compensation structure of civil servants is a significant risk of salary equity.

Fourthly, the expectation of the civil servants is diversification. We found that the salary is not the first factor for people to select the occupation of civil servants, job stability, career development, social status is the top three factors for chosen by civil servants in the survey. Improving the living condition through increase revenue is urgent need. In addition, civil servants have multiple working targets in the development of our society, we should pay attention to promotion of job titles, promotion of technical titles, which brings civil servants' working satisfaction.

\section{General Idea and Measures to Improve Compensation System of China's Civil Servants}

\section{A. Design the Compensation of Individual Fairness}

\section{1) Increasing the Weight of Human Capital Investment during Calculating the Salary}

Civil servants who received higher education pay more money compared to people who received lower education, however, these costs can not rely on the current pay system of civil servants for compensation. Therefore, remuneration design should be based on the civil servants at different education levels, considering the cost of their own human capital value. That is to say, we should appending earnings in order to achieve individual pay equity of civil servants. Our country can learn excellent experience from Korea. Korea is devoting much attention to the role of education in the civil service career, regarding education as an important indicator of the quality of the civil servants. In Korea, difference of human capital at different educational level is more than $30 \%$, which encourages civil servants to improve their academic levels to some extent [6].

\section{2) Establish the Job Evaluation System}

Evaluating job scientifically is based on value of labor, highlighting individual effort and fair distribution. It is established salary standard according to job responsibility, skill level, working conditions and environmental quality, it is also the prerequisite of achieving salaries equity between different positions. However, the existing compensation of civil servants pay too much emphasis on the determination of position level and working hours, ignoring job characteristics and individual performance. That can not be evaluated the effect of the civil servants objectively.

Therefore, designing compensation system standard of civil servants can refer to that of enterprises, besides ensuring the basic salary of civil servants, enterprises emphasize on individual capability and job performance. The more performance, the higher salaries are, so as to affirm individual contributions and mobilize the enthusiasm and creativity. Meanwhile, low efficiency and poor work performance of civil servants may pay lower accordingly, in order to achieve negative incentive function. Moreover, performance pay will be flexible to help the government reduce the financial pressure on expenditure, and improve government service level and administrative efficiency.

\section{B. Design of compensation of level fairness}

\section{1) Establish a Scientific Compensation Balance Comparison Mechanism}

From the practice of pay administration of civil servants in other countries, most countries rely on scientific salary survey system to adjust pay level with reference to corporate. According to the experience in Japan, government conduct the compensation level survey at least every five years. Meanwhile, the compensation setting standard of civil servants should follow the scientific salary balance mechanism [7]. On the basis of the job description, defining work elements contained in key positions, such as the ability, mental strength, working environment and skill requirements, finding relative jobs in enterprise based on primary work elements. Then they track wage of reletive position to follow external pay equity to attract and stable civil servants .

\section{2) Establish a Fair Compensation Increasing Mechanism for Civil Servants}

The current salary increasing mechanism of current civil servants is basically relying on to enhance level and increacing hours. As the number of civil servants at the county level government agencies accounted for over $70 \%$, the majority of civil servants can not raise their wages or job promotion. That is to say, in order to ensure that every civil servant has equitable salary growth, we should increase the wage setting level, making wage policy inclined to most junior civil servants. In addition, the government should regularly adjust the salary standard according to the material and cultural life of the residents, with reference to the price level increase or decrease, designing compensation system based on market change.

\section{Design of Compensation of Structural Fairness}

1) Adjust the Proportions of Wages and Benefits

In order to make the wage of civil servants incentive, the salary structure of civil servants can learn from companies that combining basic and floating wages. The basic salary of civil servants should be reflected the value of labor and salary 
protection function, according to international experience, the basic wage should account for $70 \%-80 \%$ of the total proportion of salaries to meet civil servants pursue stable psychological demands. While floating wages should account for $5 \%-20 \%$ [8]. Furthermore, technical categories of civil servants, should establish a high proportion of the performance incentive pay, which is more conducive to encouraging highlevel personnel.

\section{2) Implement the Monetization of the Civil Service Welfare System}

Monetization is the basic entry point for the reform of China's civil service welfare system, the abolition of welfare housing, taking fund the purchase and housing subsidies is the most important parts. China should pay and benefits under the existing civil service mode, learn from developed countries monetized benefits and duties of consumer items, enjoying spending levels and positions with the performance of monetary. In addition, for some expenses can not be measured by monetary welfare programs, such as paid vacation, trip, training and other projects can develop personalized welfare system based on the actual needs and preferences welfare of civil servants, in order to meet the current needs of the civil serviants benefits .

\section{3) Implement Social Insurance System of the Civil Servants}

The current insurance management of civil servants are managed by various departments, including Ministry of Labor and Social Security, Ministry of Finance, the Ministry of Health, Ministry of Civil Affairs and the unions. This bull management causes low efficency of managemnt system, responsibility alternately, which increasing administrative costs greatly. In order to reduce the burden on government's insurance payments in the future, it is necessary for the existing insurance system reform. At present, it exists civil servants insurance management fragmentation, due to interprovinces has its own management system, which will inevitably result in civil servants' insurance relationship difficult to continue or other problems. Therefore, we should establish a social insurance system coordination mechanisms, to develop a relationship between the transfer of insurance management approach, in order to prevent flow of talent because the limit of the transfer of insurance problems.

\section{References}

[1] Hui Li, "Theoretical and empirical studies of incentives abroad", Truth Seeking, no. 1, pp. 39-40, January 2009.

[2] He Zong, "Focus civil servants ranks compensation reform", Friends of Party Members and Cadres, no. 1, pp. 12-13, January 2015.

[3] Zhenzhou Luo and Yunxia Sun, "Civil servants management problems and solutions", Human Resources Development of China, no. 12, pp. 76-78, December 2010

[4] Yongjie Zhao and Xiangguo Kong, "Investigation and reflection grassroots capacity building of civil servants", Hunan Social Society, no. 5, pp. 77-80, May 2008.

[5] Jibin Fan, "Government employees and their salaries orientation", Enterprise Reform and Management, no. 5, pp. 32-33, May 2006.

[6] Zhongyang Jin, "Overview and civil service reform in Korea trend", China Pubilc Administration, no. 8, pp. 73-76, August 2005.

[7] Guangming Zhu, "Review on civil servant system reform in Japan", China Pubilic Administration, no.1, pp. 100-103, January 2010.

[8] Qiufeng He," Theory and application of civil servants salary balance mechanism", Chines Talent, no. 3, pp. 62-64, March 2008. 